\title{
Study on the Kinetics of Water Decomposition by ZrMnFe Micro Powder
}

\author{
Yong Yao*, Zhiyong Huang and Jiangfeng Song \\ Institute of Materials, China Academy of Engineering Physics, Mianyang 621907, P.R. China \\ *Corresponding author
}

\begin{abstract}
Aimed to recovery tritium from tritiated water, ZrMnFe micro powder synthesized by solvent combustion and calcium reduction was selected to decompose water vapor. The kinetics of reaction between ZrMnFe micro powder and water vapor was studied by isothermal thermogravimetric method in the temperature range $673 \mathrm{~K} \sim 773 \mathrm{~K}$ and water vapor range $2500 \times 10^{-6} \sim 10000 \times 10^{-6}$. The result shows that the effective elements in $\mathrm{ZrMnFe}$ are $\mathrm{Zr}$ and $\mathrm{Mn}$ with the corresponding products $\mathrm{ZrO}_{2}$ and $\mathrm{MnO}$. The reaction rate increased with the rising of temperature and water concentration. The reaction process fitting with non-catalytic gas-solid reaction models shows that Jander model can accurately describe the reaction process, and the reaction is one order for water vapor with the activation energy $47 \mathrm{KJ} / \mathrm{mol}$.
\end{abstract}

Keywords-ZrMnFe, water decomposition, isothermal thermogravimetric method, reaction model

\section{INTRODUCTION}

Tritium is a key substance used in fusion reactor and nuclear laboratory. Tritiated water(HTO) is a normal form of tritide, it is always produced by catalytic-oxidation in detritiation system both for normal tritium handing and in the event of tritium release[1,2]. Tritiated water is about 25000 times more radio-toxic for human bodies than tritium gas[3], and HTO self-irradiation will produce $\mathrm{HT}$ and $\mathrm{O}_{2}$ leading to explosive risk [4];in addition, HTO has strong corrosive for vessel[5]; therefore, the processing and storage of HTO in liquid must be avoided. Tritium in the chemical form of hydrogen isotope molecules is by far the safest, hence recovery tritium from tritiated water is quite important not only for tritium recycling but also for environment protection.

The decomposition of tritiated water by metal(alloy) is a simple and cost-effective method to recovery tritium and reduce tritium emission, which has been widely used in some large tritium laboratory, such as LANL,SRS,TLK[6]. The reaction principle can be expressed as: $x M+H_{2} O(g)=M_{x} O+H_{2}(g)$.In this approach, HTO vapor is converted to HT by redox reaction. The reducing material should work at relative low temperature and the material should have small hydrogen inventory to reduce tritium loss[7]. $\mathrm{ZrMnFe}$ alloy (trade mark St909) is the most suitable material to meet above requirements, but its price is as high as $\$ 4000$ $\$ 4500$ (\$US) $/ \mathrm{kg}[8]$. In our previous study, a new method named as solvent combustion and calcium reduction was used to synthesized ultrafine $\mathrm{ZrMnFe}$ alloy powder[9], the cost of alloy can be decreased dramatically by using this method.
Preliminary experiment showed that $\mathrm{ZrMnFe}$ micro powder has high reactivity to decompose water vapor, but the reaction process needs to be studied more deeply to satisfy the engineering application requirement. In the present study, the kinetics was studied by isothermal thermogravimetric method to investigate the inherent relationship between temperature, water vapor concentration and conversion rate of alloy powder. $\mathrm{H}_{2} \mathrm{O}$ was used as substitute for HTO for similar chemical property and non-radioactivity.

\section{EXPERIMENTAL}

\section{A. Material}

$\mathrm{ZrMnFe}$ alloy micro powder was synthesized by solvent combustion and calcium reduction method, the detail can be found in [9]. Certified gas mixture of $\mathrm{Ar}$ with trace $\mathrm{H}_{2}(10000 \mathrm{ppm}, 5000 \mathrm{ppm}$ and 2500ppm)was purchased from Chinese Academy of Measurement Technology.

\section{B. Thermogravimetric Kinetics Experiment}

The schematic diagram of the thermogravimetric experiment arrangement is shown in Figure 1. ZCT-A with the sensitivity of detecting weight changes on the order of 1 ug was used in the experiments. Ar was first introduced into the TG reactor chamber, and sample was heated to the reaction temperature with the protecting of Ar. Then $\mathrm{H}_{2} \mathrm{O} / \mathrm{Ar}$ mixture was sent into TGA, the mass variation of sample and reaction time was recorded by computer, the conversion rate was described by the sample mass increased divided by the maximum mass increment. Quantitative water was produced by the following reaction: $\mathrm{H}_{2}+\mathrm{CuO}=\mathrm{Cu}+\mathrm{H}_{2} \mathrm{O}$ in $\mathrm{CuO}$ bed, the bed temperature was keeping at $773 \mathrm{~K}$ and $\mathrm{CuO}$ was overloading to ensure that all hydrogen molecule be oxidized to water. Water concentration was monitored by dew point meter (MichellCermax). Pre-experiment was carried out first to eliminate the influence of external diffusion by increasing the flow velocity and scattering sample uniformly on platinum crucible.

\section{Kinetics parameter fitting}

The reaction between $\mathrm{ZrMnFe}$ micro powder and water vapor is a typical non-catalytic gas-solid reaction, several mechanics equations(presented in Table 1)are usually used to describe the reaction process. 


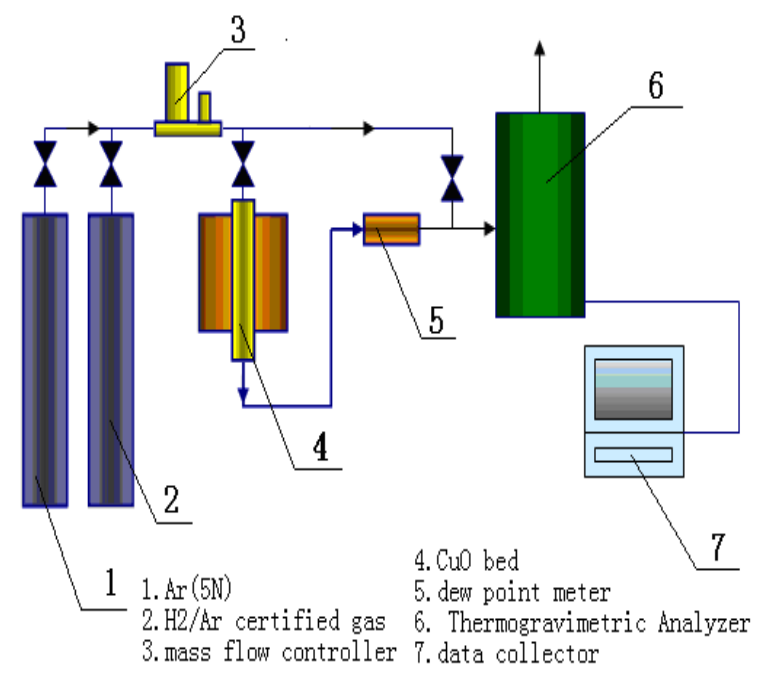

FIGURE I. THE SCHEMATIC DIAGRAM OF THERMOGRAVIMETRIC EXPERIMENT

TABLE I. REACTION MECHANISMS AND ALGEBRAIC EXPRESSIONS[10]

\begin{tabular}{|c|c|c|c|}
\hline $\begin{array}{c}\text { Serial } \\
\text { number }\end{array}$ & Reaction mechanism & $f(x)$ & $\begin{array}{l}G(x)(\text { integrated } \\
\text { forms of } f(x))\end{array}$ \\
\hline D1 & $\begin{array}{l}\text { One-dimensional } \\
\text { diffusion }\end{array}$ & $(1 / 2) x$ & $\mathrm{x}^{2}=\mathrm{kt}$ \\
\hline D2 & $\begin{array}{l}\text { Two-dimensional } \\
\text { diffusion }\end{array}$ & $\begin{array}{c}1 /[-\ln (1- \\
\mathrm{x})]\end{array}$ & $(1-x) \ln (1-x)=k t$ \\
\hline D3 & $\begin{array}{l}\text { Three-dimensional } \\
\text { diffusion } \\
\text { (Jander eq.) }\end{array}$ & $\begin{array}{c}3(1- \\
\mathrm{x})^{2 / 3} /\{2[1- \\
\left.\left.(1-\mathrm{x})^{1 / 3}\right]\right\}\end{array}$ & {$\left[1-(1-\mathrm{x})^{1 / 3}\right]^{2}=\mathrm{kt}$} \\
\hline D4 & $\begin{array}{l}\text { Three-dimensional } \\
\text { diffusion } \\
\text { (Ginstein-Brounshtein } \\
\text { eq.) }\end{array}$ & $\begin{array}{c}(3 / 2)[(1- \\
\left.x)^{-1 / 3}-1\right]\end{array}$ & $\begin{array}{c}1-2 \mathrm{x} / 3-(1- \\
\mathrm{x})^{2 / 3}=\mathrm{kt}\end{array}$ \\
\hline $\mathrm{R} 1$ & $\begin{array}{l}\text { First-order reaction } \\
\text { (unimolecular decay } \\
\text { law) }\end{array}$ & $(1-x)$ & $-\ln (1-x)=k t$ \\
\hline $\mathrm{R} 2$ & $\begin{array}{l}\text { Phase-boundary } \\
\text { controlled } \\
\text { (contracting cylinder) }\end{array}$ & $(1-x)^{1 / 2}$ & $1-(1-\mathrm{x})^{1 / 2}=\mathrm{kt}$ \\
\hline R3 & $\begin{array}{l}\text { Phase-boundary } \\
\text { controlled } \\
\text { (contracting sphere) }\end{array}$ & $(1-x)^{2 / 3}$ & $1-(1-x)^{1 / 3}=k t$ \\
\hline Al & $\begin{array}{l}\text { Two-dimensional } \\
\text { growth of nuclei }\end{array}$ & $\begin{array}{c}2(1-x)[- \\
\ln (1-x)]^{1 / 2}\end{array}$ & {$[-\ln (1-\mathrm{x})]^{1 / 2}=\mathrm{kt}$} \\
\hline A2 & $\begin{array}{l}\text { Three-dimensional } \\
\text { growth of nuclei }\end{array}$ & $\begin{array}{c}3(1-x)[- \\
\ln (1-x)]^{2 / 3}\end{array}$ & {$[-\ln (1-\mathrm{x})]^{2 / 3}=\mathrm{kt}$} \\
\hline
\end{tabular}

In Table1, G(x) is the integral form of mechanism model, $f(x)$ is the differential form. The function can be described as following:

$$
\begin{gathered}
G(X)=k \cdot t \\
\frac{d X}{d t}=k \cdot f(X)
\end{gathered}
$$

where $\mathrm{k}$ is the apparent reaction rate constant, $\mathrm{t}$ is the reaction time, $X$ is the conversation rate. If the $G(x) \sim t$ can be described by a line, it showed that this model can be used to described the reaction process, and the corresponding differential equation will be the reaction kinetics equation.

\section{RESULTS AND DisCUSION}

\section{A. Characterization of Material}

Figure 2 displays the SEM image of $\mathrm{ZrMnFe}$ micro powders after reaction, which is similar with the powder before reaction. It can be seen that the powders are ultra-fine particles with the size about 500nm.

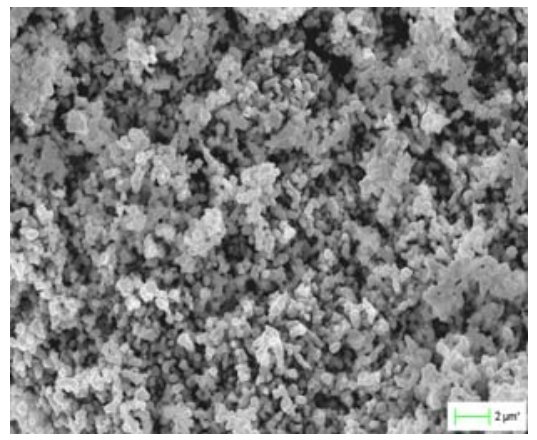

FIGURE II. SEM IMAGES OF ZRMNFE MICRO POWDER

Figure 3 shows the XRD spectrum. The alloy power only consists of $\mathrm{ZrMnFe}$ phase with $\mathrm{C} 14$ structure before reaction. After reaction, the $\mathrm{ZrMnFe}$ phase disappeared, and the phase was comprised of $\mathrm{ZrO}_{2}, \mathrm{MnO}$ and $\mathrm{Fe}$. This indicates that $\mathrm{Zr}$ and $\mathrm{Mn}$ are effective elements to react with $\mathrm{H}_{2} \mathrm{O}$, while $\mathrm{Fe}$ is still kept in metal status, which may be attributed to the slow reaction rate between $\mathrm{Fe}$ and $\mathrm{H}_{2} \mathrm{O}$. The process is similar to the reaction between ST909 alloy and water vapor[6].

From the alternation of phases, the reaction equation could be speculated as (3):

$$
\mathrm{ZrMnFe}+3 \mathrm{H}_{2} \mathrm{O}=\mathrm{ZrO}_{2}+\mathrm{MnO}+\mathrm{Fe}+3 \mathrm{H}_{2}
$$

The sample mass increment is $23 \%$ calculated from Eq.3, which is equal to the mass increment of sample completely reacted in thermogravimetric experiment.

\section{B. The Effect of Temperature and Water Concentration on Reaction Rate}

The conversion rate of $\mathrm{ZrMnFe}$ micro powder in the temperature range $(673 \mathrm{~K}-773 \mathrm{~K})$ with different water concentration is given in Figure 4.It can be seen that the reaction rate has similar trend at different concentrations: rising temperature accompanied by increasing reaction rate, the reaction rate at $723 \mathrm{~K}$ is about 2 times faster than that at $673 \mathrm{~K}$; but the reaction rate at $773 \mathrm{~K}$ and $723 \mathrm{~K}$ differs not too much. It is also found that the higher water concentration resulted in higher reaction rate; for example, in the case of $723 \mathrm{~K}$, the time for entirely conversion is about $110 \mathrm{~min}, 65 \mathrm{~min}, 35 \mathrm{~min}$ for 2500ppm, 5000ppm, 10000ppm, respectively. 


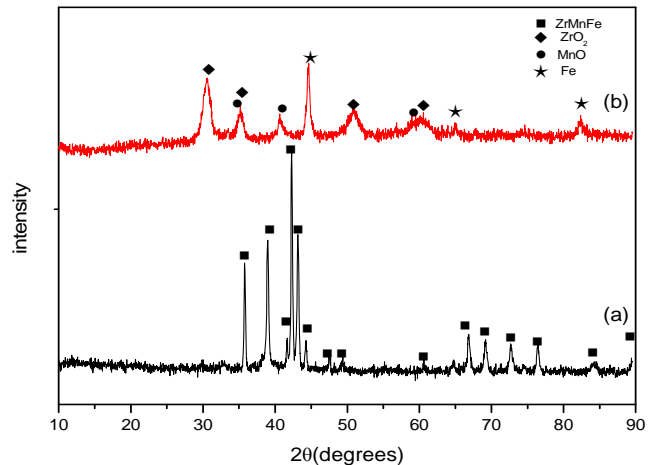

FIGURE III. XRD SPECTRUM OF ZRMNFE MICRO POWDER

(A) BEFORE REACTION, (B) AFTER REACTION
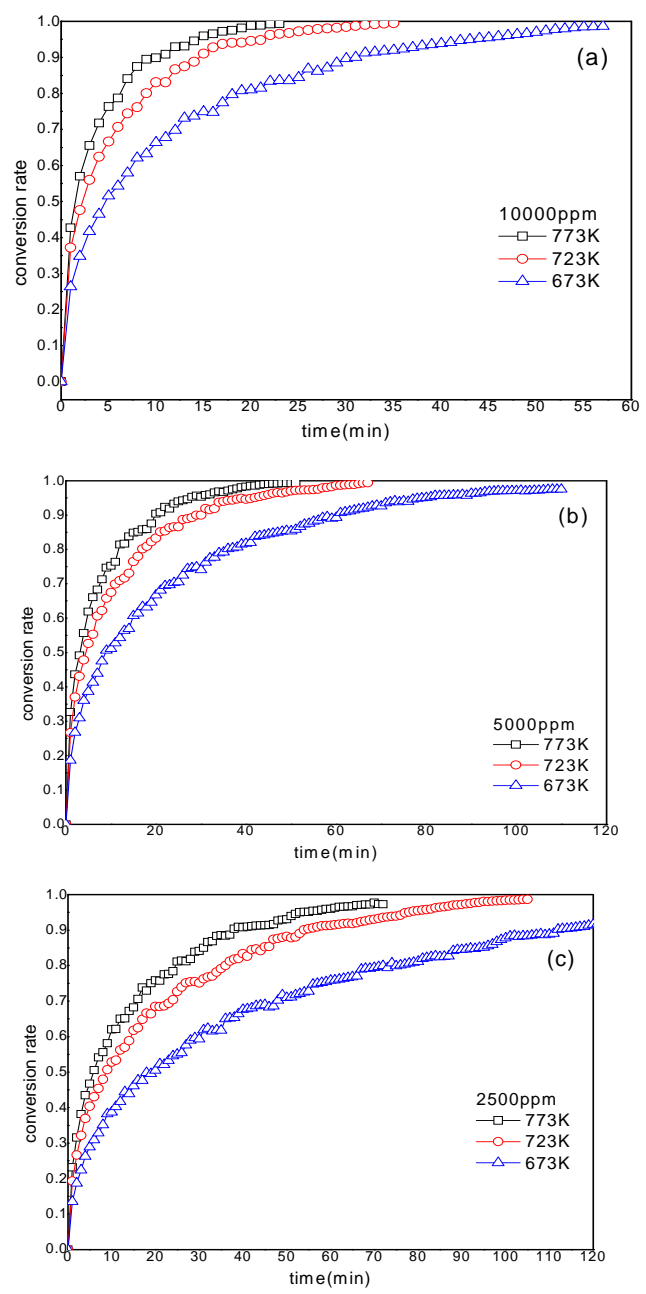

FIGURE IV. THE EFFECT OF TEMPERATURE AND CONCENTRATION ON REACTION RATE

(A)10000PPM;(B)5000PPM;(C)2500PPM

\section{Kinetics Parameters Fitting}

The $x-t$ data at $723 \mathrm{~K}$ and $10000 \mathrm{ppm}$ was first taken into the $\mathrm{G}(\mathrm{x})$ equations in Table1 for attempt, the fitting line of $\mathrm{G}(\mathrm{x})$-t curve for each equation was obtained, and the square of relative correlation $\left(\mathrm{R}^{2}\right)$ is shown in Table 2, which is used to evaluate suitability of the reaction mechanism equation. The result shows that Jander model(D3) is the best to describe the reaction process for $\mathrm{R}^{2}=0.995$, which is the largest and the most close to 1 .

Jander model was used to deal with all the data at different temperature and water concentration. The $\left[1-(1-x)^{1 / 3}\right]^{2} \sim t$ curves is presented in Figure 5. It can be found that all curves have good linearity, so this equation is suitable to describe the reaction process at different conditions. The apparent rate constants $(\mathrm{k})$ was calculated from the slope of the $\left[1-(1-x)^{1 / 3}\right]^{2} \sim t$ curves, the results are given in Table 3 . It indicates that the rate constant increased with temperature and water concentration.

TABLE II. THE RELATIVE CORRELATION OF DIFFERENT MODELS

\begin{tabular}{|l|l|l|l|l|l|l|l|l|l|}
\hline MODEL & D1 & D2 & D3 & D4 & R1 & R2 & R3 & A1 & A2 \\
\hline $\mathrm{R}^{2}$ & 0.87 & 0.93 & 0.995 & 0.986 & 0.76 & 0.88 & 0.96 & 0.8 & 0.96 \\
\hline
\end{tabular}
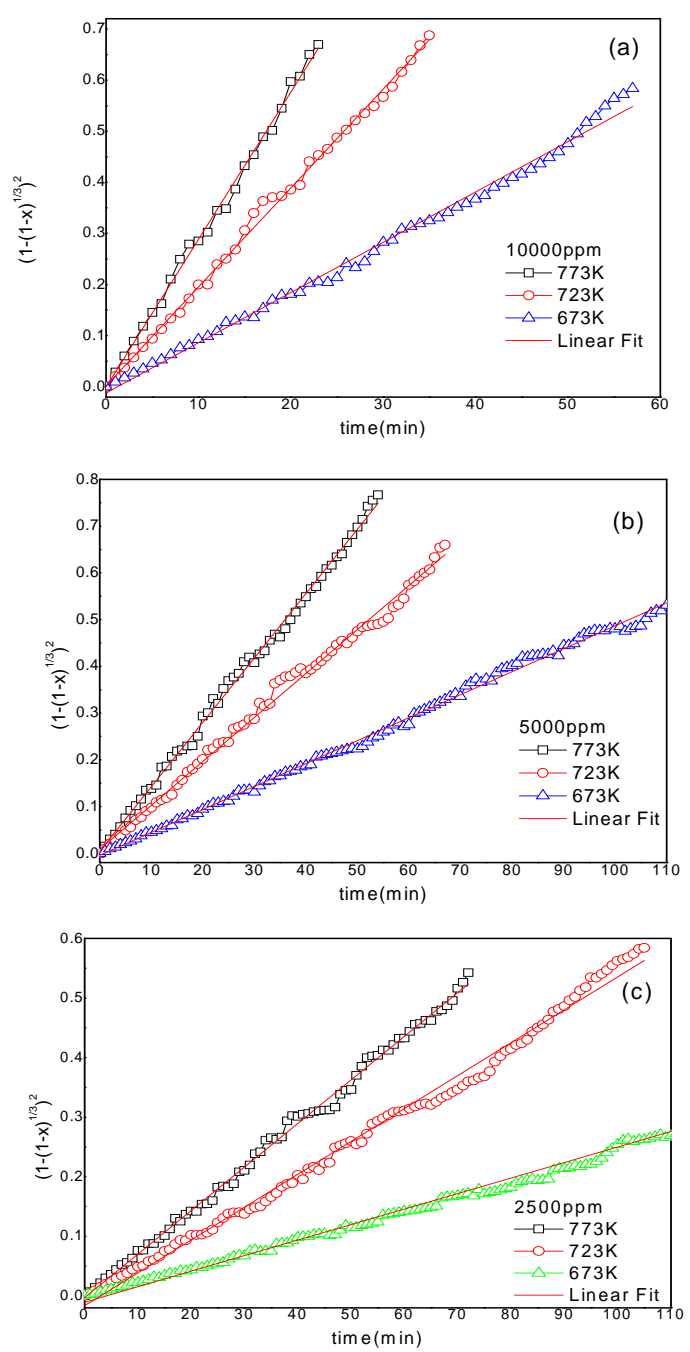

FIGURE V. THE $[1-(1-X) 1 / 3] 2 \sim$ T CURVES AT DIFFERENT TEMPERATURES

(A).10000PPM;(B).5000PPM;(C).2500PPM 
The relation of rate constant and $\mathrm{H}_{2} \mathrm{O}$ concentration is plotted in Figure 6. It shows that $\mathrm{k}$ is proportional to water concentration, so the reaction is first order for water vapor.

According to Arrhenius equation: $k=A \exp \left(-E_{a} / R T\right)$ [11], the logarithmic form could be written as: $\ln k=\ln A-E_{a} /(R T)$, the relation of $\ln \mathrm{k} \sim 1 / \mathrm{T}$ is plotted in Figure 7. It shows that the curves are approximate lines with uniform slope, water concentration have no effect on slope of curves owing to activity energy is the instinct character of material; however, intercept is increased with the rise of water concentration, this is due to that higher concentration means larger pre-exponential factor A. The activation energy could be calculated from the slope of these curves, the average value is $47 \mathrm{KJ} / \mathrm{mol}$ from the three concentration.

TABLE III. THE APPARENT RATE CONSTANTS AT DIFFERENT CONDITIONS

\begin{tabular}{|c|c|c|c|}
\hline Temperature & $\begin{array}{c}\text { Water vapor } \\
\text { concentration (ppm) }\end{array}$ & $\operatorname{Kexp}^{-3} \mathrm{~s}^{-1}$ & $\mathrm{R}^{2}$ \\
\hline \multirow{3}{*}{$773 \mathrm{~K}$} & 10000 & 2.89 & 0.992 \\
\cline { 2 - 4 } & 5000 & 1.4 & 0.993 \\
\cline { 2 - 4 } & 2500 & 0.73 & 0.997 \\
\hline \multirow{3}{*}{$723 \mathrm{~K}$} & 10000 & 1.91 & 0.994 \\
\cline { 2 - 4 } & 5000 & 0.94 & 0.995 \\
\cline { 2 - 4 } & 2500 & 0.5 & 0.996 \\
\hline \multirow{3}{*}{$673 \mathrm{~K}$} & 10000 & 0.94 & 0.993 \\
\cline { 2 - 4 } & 5000 & 0.49 & 0.994 \\
\cline { 2 - 4 } & 2500 & 0.26 & 0.998 \\
\hline
\end{tabular}

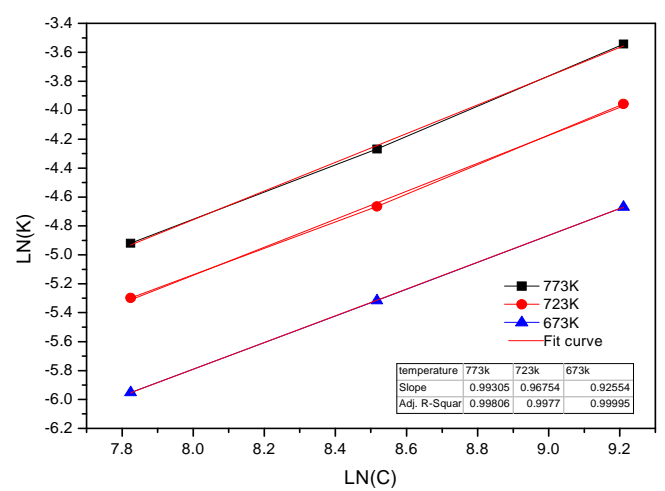

FIGURE VI. THE RELATION OF K AND H2O CONCENTRATION

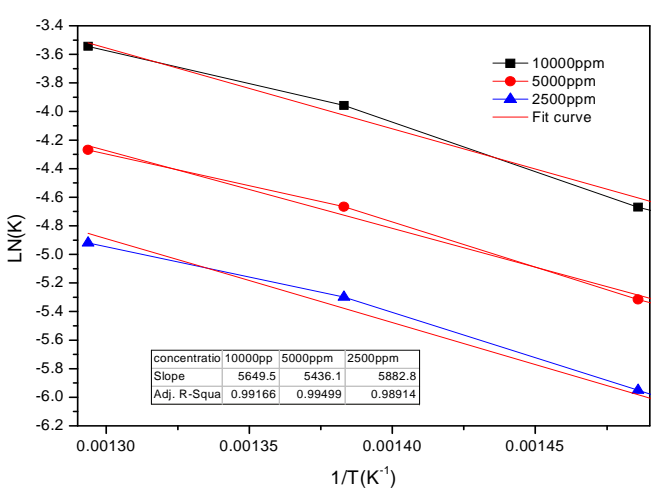

FIGURE VII. THE RELATION OF LN(K) $1 /$ T
According to the differential form of Jander model, the kinetics equation can be described as (4):

$$
d X / d t=0.00676 \exp \left(-47 \times 10^{3} / R T\right) \cdot C \cdot(1-x)^{2 / 3} / 1-(1-x)^{1 / 3}
$$

According to (4), the apparent rate constant at different temperature and concentration can be written as:

$$
k_{\text {cal }}=0.00676 \exp \left(-47 \times 10^{3} / R T\right) \bullet C
$$

In order to estimate the deviation, the calculated rate constant (Kcal) and experimental rate constant (Kexp) are given in Figure 8. It can be seen that the deviation is less than $12 \%$. Therefore, it showed that the Jander model is suitable to describe the reaction between $\mathrm{ZrMnFe}$ micro powder and water vapor. Jander model is a complex of one dimensional diffusion model (D1) and three dimensional phase-boundary reaction model (R3), it is always used to present the gas-solid noncatalytic reaction for ultrafine particle. For example, Kang et al has used this model to describe the reduction reaction of micro powder $\mathrm{Fe}_{2} \mathrm{O}_{3}, \mathrm{MnFe}_{2} \mathrm{O}_{4}$ and $\mathrm{ZnFe}_{2} \mathrm{O}_{4}$ with hydrogen and the following oxidation reaction of reduced product with water vapor [10].

\section{CONClUSIONS}

The kinetic of the water vapor decomposition reaction by $\mathrm{ZrMnFe}$ micro powder synthesized by solvent combustion and calcium reduction was studied by isothermal thermogravimetric method. The effective elements in $\mathrm{ZrMnFe}$ are $\mathrm{Zr}$ and $\mathrm{Mn}$ with the corresponding products $\mathrm{ZrO}_{2}$ and $\mathrm{MnO}$. The reaction process can be described by Jander diffusion model in the temperature $673 \mathrm{~K} \sim 773 \mathrm{~K}$ and water vapor range $2500 \times 10^{-6} \sim$ $10000 \times 10^{-6}$. The kinetics equation can be expressed as: [1-(1$\left.\mathrm{x})^{1 / 3}\right]^{2}=\mathrm{kt}$. The apparent rate constant $(\mathrm{k})$ increases with temperature and water concentration, the reaction is one order for water concentration, and the reaction activation energy is $47 \mathrm{~kJ} / \mathrm{mol}$ calculated from Arrhenius equation.

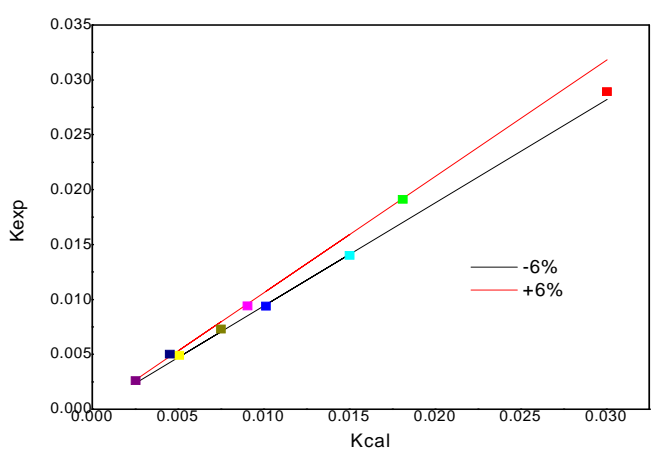

FIGURE VIII. THE COMPARISON BETWEEN KCAL AND KEXP

\section{REFERENCES}

[1] F. Ghezzi, W. T. Shmayda, and N. Venkataraman, "Efficient HTO reduction using a Zr-FeMn alloy", Fusion Engineering and Design, vol. 28,pp.367-372,1995. 
[2] H. Yoshida, O. Kveton, and J. Koonce, "Status of the ITER Tritium Plant design", Fusion Engineering and Design, vol. 39-40, pp. 875$882,1998$.

[3] S. Fukada, Y. Toyoshima, and M. Nishikawa, " $\mathrm{Zr} 2 \mathrm{Fe}$ and $\mathrm{Zr}\left(\mathrm{Mn}_{0.5} \mathrm{Fe}_{0.5}\right)_{2}$ particle beds for tritium purification and impurity removal in a fusion fuel cycle", Fusion Engineering and Design, vol. 49-50, pp. 805809,2000 .

[4] T. Hayashi, "Safety handling characteristics of high-level tritiated water", Fusion Engineering and Design, vol. 81, pp. 1365-1369, 2006.

[5] G. Bellanger, "Localized corrosion of $316 \mathrm{~L}$ stainless steel in tritiated water containing aggressive radiolytic and decomposition products at different temperatures", Journal of Nuclear Materials, vol. 374, pp. 20$31,2008$.

[6] F. Ghezzi, W. T. Shimayda, and G. Bonizzoni, "An experimental investigation of the efficiency of HTO reduction by Zr-Fe-Mn getter alloy", Fusion Technology, vol. 31, pp. 75-78, 1997.

[7] F. Ghezzi, and C. Boffito, "Pressure-concentration-temperature characterization of St909 getter alloy with hydrogen", Vacuum, vol. 47, pp. 991-995, 1996.

[8] J. E. Klein, and J. S. Holder, "Screening tests for improved methane cracking materials", Fusion Science and Technology, vol. 54,pp. 611614,2008 .

[9] Y. Yao, D. L. Luo, T. Tang, C. L. Jiang, "Synthesis of ZrMnFe micropowder by solvent combustion-Calcium reduction", Materials Science and Engineering of Powder Metallurgy, vol. 17, pp. 208-213, 2012.

[10] K. S. Go, S. R. Son, and S. D. Kim, "Reaction kinetic of reduction and oxidation of metal oxides for hydrogen production", International Journal of Hydrogen Energy, vol. 33, pp. 5986-5995, 2008.

[11] Y. X. Hua, "An Introduction to Kinetics of Metallurgical Process", Metallurgical Industry Press, Bejing, 2004. 